\title{
Chólera Morbus no curato de Nossa Senhora Imaculada Conceição do Porto das Caixas (RJ): a epidemia relatada nos periódicos
}

\section{Cholera Morbus in the parsonage of Our Lady Immaculate Conception of Porto das Caixas (RJ): the epidemic reported in the periodicals}

\section{Mirian Cristina Siqueira de Cristo}

Universidade Salgado de Oliveira

\section{Resumo}

O presente artigo analisa a epidemia da Chólera Morbus no curato de Nossa Senhora Imaculada Conceição do Porto das Caixas no ano de 1855 , e como a doença foi retratada nos periódicos do período. O curato de Nossa Senhora Conceição do Porto das Caixas (RJ) pertencia à então Vila de São João de Itaborahy e, no início do século XIX, quando ainda tinha a nomenclatura de Arraial de Nossa Senhora Imaculada Conceição do Porto das Caixas, já tinha sido atacada por outra mortífera onda de doenças, que ficaram conhecidas pelo nome de "febres do Macacu". A epidemia da Chólera Morbus, que desembarcou nos portos da província do Rio de Janeiro, chegou na localidade através do transporte de gêneros e passageiros da corte para o interior do recôncavo da Guanabara, vitimando, em sua maioria, a população escrava do curato.

Palavras-chave: Chólera Morbus; Curato de Nossa Senhora Imaculada Conceição do Porto das Caixas; Periódicos.

\section{Abstract}

The present article analyzes the Chólera Morbus epidemy in the parsonage of Our Lady of the Immaculate Conception of Porto das Caixas, in 1855 , and how the disease was portrayed in periodicals. This parsonage belonged to the so called São João de Itaborahy town, and in the early nineteenth century, when it still had the nomenclature of Camp of Our Lady of the Immaculate Conception of Porto das Caixas, it had already been attacked by another deadly wave of diseases, known as "Macacu's fever. The Chólera Morbus epidemy, which landed in the ports of the province of Rio de Janeiro, arrived in the locality by the transportation of goods and passengers from the court to the interior of the Guanabara concave, victimizing mostly the slave population of the parsonage.

Keywords: Chólera Morbus; Parsonage of Our Lady of the Immaculate Conception in Porto de Caixas; Periodicals. 


\section{Dossiê

\section{I n t r o d u ça}

A o andar pela precária estrada de paralelepípedos do $2^{a}$ Distrito de Porto das Caixas, na cidade de Itaboraí, Rio de Janeiro, moradores e eventuais visitantes, em sua maioria, desconhecem a riqueza e complexidade histórica ali envolvidas, a começar pela idade da localidade, que existe há pelo menos 422 anos. Sempre lembrada como o local em que "o Cristo crucificado sangrou" - ponto, segundo os fiéis, de inúmeros milagres -, Porto das Caixas possuiu uma enorme importância econômica, social e política durante o século XIX, tanto para a província do Rio de Janeiro, quanto para o próprio Império. As casas simples da Avenida Nossa Senhora

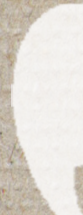

As áreas com núcleos populacionais no entorno da Baía de Guanabara e seus portos fluviais, como o Porto das Caixas, foram essenciais para viabilizar o transporte da produção açucareira dos primeiros engenhos. O aproveitamento dos rios do recôncavo guanabarino favoreceu o desenvolvimento econômico da região, por ser uma forma rápida e barata de transporte da produção em direção ao porto do Rio de Janeiro (CEICER \& SANTOS, 1954, p. 4). da Conceição, o pouco comércio, a usina de álcool de mandioca abandonada e o riacho que corta o local não demonstram nem a sombra da opulência arquitetônica que outrora teve a região, que além de ter sido um dos primeiros locais a serem ocupados no processo de interiorização portuguesa após a expulsão dos franceses, foi considerado o terceiro porto fluvial em importância comercial para a província do Rio de Janeiro no século XIX, pertencente ao recôncavo da Baía de Guanabara (RELATÓRIO DO PRESIDENTE DA PROVÍNCIA, 1857, p. 69).

As áreas com núcleos populacionais no entorno da Baía de Guanabara e seus portos fluviais, como o Porto das Caixas, foram essenciais para viabilizar o transporte da produção açucareira dos primeiros engenhos. 0 aproveitamento dos rios do recôncavo guanabarino favoreceu o desenvolvimento econômico da região, por ser uma forma rápida e barata de transporte da produção em direção ao porto do Rio de Janeiro (CEICER \& SANTOS, 1954, p. 4). 
Ailton Fernandes da Rosa Júnior (2014, p. 37-58) reafirmou a relevância dos cursos de água para o deslocamento, não somente da produção dos engenhos, mas também dos alimentos essenciais para o abastecimento da crescente cidade de São Sebastião do Rio de Janeiro (em especial a farinha de mandioca, arroz e feijão), e até das madeiras, fossem sob a forma de tábuas para a construção civil e naval, ou reduzidas à forma de lenha e carvão. Para este autor, os rios da região do recôncavo da Baía de Guanabara tiveram a função estratégica, pois através de suas águas circularam não apenas os produtos essenciais à vida citadina, mas também pessoas, hábitos, informações e tradições culturais.

O arraial do Porto das Caixas foi extremamente beneficiado pelo comércio fluvial e continuou a crescer gradativamente durante o século XVII. Em meados desse século, o porto fluvial do arraial do Porto das Caixas já tinha 14 barcos para o transporte de mercadorias, embarcando quase todo o açúcar dos oitenta engenhos das regiões próximas (FORTE, 1937, p. 53). Daí a mudança do nome da localidade: o açúcar que chegava nos lombos das mulas em bruacas ${ }^{1}$ de couro, ficava armazenado em caixas ao longo do Rio da Aldeia, esperando o embarque nas faluas ${ }^{2}$ - assim a localidade ficou conhecida como Porto das Caixas (Cf. SATHLER, 2003, p. 50; PINTO, 1832, p. 504; ROSEDAHL, 1995, p. 58).

Portos fluviais semelhantes ao do arraial do Porto das Caixas contribuíram para uma reorganização espacial do seu entorno, pois a vida e a dinâmica das povoações locais giravam em torno dessas estruturas comerciais. Além das igrejas, câmaras, delegacias, grandes fazendas, comércio e cemitérios se posicionaram ao redor dos portos que recebiam os produtos para o transporte até o Rio de Janeiro e, através dessa estruturação, nasceram as vilas de comércio. Segundo Rafael da Silva Oliveira (2007, p. 139), as chamadas vilas de comércio registraram um período de importante funcionalidade, sobretudo através da utilização de seus portos fluviais, atingindo status de cidade por conta do papel concentrador que exerciam. Apesar de nunca ter alcançado o título de vila ou cidade, o arraial do Porto das Caixas èstruturou-se com o mesmo modus operandi. Nota-se, então, que o Porto das Caixas assumiu dois papéis: o do povoado de comércio e o do porto fluvial propriamente dito, como se pode observar na descrição de Manuel Aires de Casal (1976, p. 199):

Um terço de léguia a leste da paróquia de Tambi, e ainda no seu distrito está o arraial denominado Porto das Caixas, com Ermida de N. Senhora da Conceição, sobre a direita do Rio da Aldeia, um pouco abaixo da foz do da Varge, e um pouco mais doutro terço acima da sua confluência

1 Bruacas eram confeccionadas com couro de boi amaciado na água, ajustadas e cozidas dentro de uma caixa rude com tampa, deixando-a secar. Tornavam-se duras e resistentes, sendo utilizadas para o transporte de diversos gêneros, como açúcar, milho, café etc.

2 Embarcação pequena que navega a remos ou à vela. 
com o Macacu, que fica meia légua abaixo da do Caceribu. É o entreposto das produções do distrito de Taparocá, e das freguesias limítrofes; e onde se embarca mais açúcar do que em todos os outros portos do recôncavo.

Desde o começo da ocupação do recôncavo da Baía de Guanabara, o porto fluvial do arraial do Porto das Caixas teve a função de entreposto comercial, sendo caminho de trocas de produtos e de passagem de tropas que carregavam o açúcar das fazendas e engenhos próximos (NOCUEIRA, 2009, p. 21). Após o século XVII e o favorecimento da produção de gêneros alimentícios e da cana-de-açúcar, a região na qual estava inserido o arraial do Porto das Caixas e o seu porto fluvial favoreceu-se também do transporte da produção aurífera de Minas Cerais no século XVIII (ROSA JUNIOR, 2014, p. 35). Segundo Antônio Carlos Jucá de Sampaio (2016), as profundas transformações que a economia fluminense passou acabaram por se refletir nas características do grupo mercantil já existente, sobretudo em sua elite. Para Sampaio, de fato a passagem do século XVII para o XVIII viu essa elite mercantil constituir-se enquanto grupo social autônomo face à elite agrária. Esse fato não significou a separação total entre as duas elites, mas sim a criação de uma esfera tipicamente mercantil de atuação, que não existiu no território fluminense no século XVII. Mais do que isso, essas transformações caracterizaram esse novo grupo como a elite colonial setecentista, responsável direta pela própria reprodução da sociedade fluminense por meio do controle dos mecanismos de crédito e da oferta de mão de obra escrava.

Milton Santos (2006, p. 136) mostrou que essas redes comerciais formadas pela elite mercantil e agrária se integraram e se desintegraram, destruíram velhos recortes espaciais e criaram novos, sendo marcadas por um caráter instável, móvel e inacabado, que corrobora com um aspecto importante na configuração das redes territoriais, como aconteceu com o arraial do Porto das Caixas. Rafael da Silva Oliveira (2007, p. 132) também relatou as mudanças da organização espacial como fruto do acúmulo do trabalho humano estruturado através dos tempos, numa relação dialética em que o espaço, em sua totalidade, sofreu mutações, pois a sociedade, estimulada por questões de ordem capital, cultural e emocional, se deslocou, se transformou, se construiu e se recriou. Apesar disso, o domínio da elite mercantil sobre as principais rotas de comércio está longe de ser uma originalidade do Rio de Janeiro setecentista. De fato, constitui uma característica estrutural das sociedades de Antigo Regime.

Para Laura de Mello e Souza (2006, p. 67), o que houve em nossos trópicos, sem dúvida, foi uma expressão muito peculiar das sociedades do Antigo Regime europeu, que integraram, qualificaram e definiram não só as relações sociais como as comerciais, beneficiando o sistema colonial. Esses processos de organizações espaciais, rotas de comércio e relações comerciais 
influenciadas pelo Antigo Regime moldaram de forma específica a localidade do arraial do Porto das Caixas, sua população e arquitetura, que foram totalmente voltadas para as relações comerciais que ali ocorreram e pelos novos caminhos que surgiram, transformando-se e reconstruindo-se espacialmente:

Já a região de Porto das Caixas consolidava-se como importante entreposto comercial. Em seu porto eram desembarcados, em caixas, além do açúcar, a produção agrícola transportada pelos muares. Trapiches e armazéns começaram a ser erguidos para armazenar essa produção até o embarque para o porto e para a cidade do Rio de Janeiro (ROCHA et al, 2011, p. 70).

Vale ressaltar a importância das tropas para a manutenção do mercado interno descrito. Para Pandiá Calógeras (1927, p. 12) e Satie Mizubuti (2001, p. 47), a figura do tropeiro, além de ter tido um sentido social (pois foi um facilitador da aproximação entre o mundo rural e urbano), também adquiriu uma grande importância na formação de novos núcleos populacionais, já que com suas tropas de muares transportavam mercadorias a longas distâncias, semeando "embriões de cidades" à beira das estradas e nos locais de pouso.

Com a chegada da família real ao Brasil em 1808, essa movimentação de tropas comerciais com gêneros de primeiras necessidades, voltados para o conșumo interno, consolidou-se, e novas rotas surgiram para suprir o abastecimento de gêneros alimentícios para a recém-chegada população do Rio de Janeiro. Para Maria Odília Leite da Silva Dias (2005, p. 12-15), a chegada da família real ao Brasil já significou por si só uma ruptura política interna, com significativas mudanças econômicas e políticas, principalmente no mercado carioca. Essas mudanças que ocorreram no mercado carioca a partir da concretização e do monopólio comercial acabaram por definir o Rio de Janeiro como polo drenador de vários produtos (LENHARO, 1979, p. 33), que chegavam ao porto principal através de inúmeros portos fluviais localizados ao entorno da Baía de Guanabara, em especial no seu recôncavo, onde estava localizado o Porto das Caixas. Segundo Dias (2005, p. 19-29), foi a vinda da corte portugu'esa para o Brasil e a sua fixação no Rio de Janeiro que deu início ao processo de transformação da colônia em metrópole interiorizada, acentuando o predomínio da classe dos comerciantes.

Apesar dessa consolidação comercial alcançada após a chegada da família real no Brasil, o arraial do Porto das Caixas, a partir de 1828, começou a atravessar sérios problemas epidêmicos, que resultaram em grandes mudanças políticas e administrativas. $\mathrm{O}$ arraial que pertencia à Vila Santo Antônio de Sá, primeiro núcleo urbano com status estabelecido na capitania do Rio de Janeiro (CABRAL, 2007, p. 136), era cortado pelo Rio Aldeia, um dos afluentes do Rio Macacu, ambos parte da baixada da Guanabara - uma planície extensa, espraiada em torno da 
Baía e drenada por pequenos rios que nela deságuam. Por ser uma planície, o declive é muito pequeno e, na época das chuvas, abundantes no clima tropical atlântico, o aumento de nível fluvial faz com que a água acumulada se espalhe pela planície. Como o solo é constituído por uma mistura de argila e areia, nas áreas mais argilosas o solo retém a umidade, formando extensas áreas de brejo, ou seja, de terrenos baixos e alagadiços cobertos por vegetação rasteira (MACHADO, 1998). Toda essa disposição geográfica, aliada ao desmatamento local devido à extração de madeira e ao abandono das plantações de cana-de-açúcar, favoreceram o assoreamento dos rios e a estagnação das águas nos pântanos, criando as condições perfeitas para o desenvolvimento de uma série de surtos de epidemias de caráter tifoide e bilioso.

Esses surtos, que se iniciaram nos fins do ano de 1828, assolaram a região da Vila Santo Antônio de Sá, espalhando-se também para o resto da província (MARCíLIO, 1993, p. 63). Conhe-

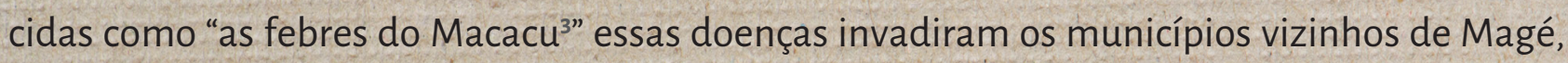
Cuapimirim, Porto Estrela, Pilar, Inhomirim, Iguaçu e Irajá. Na cidade do Rio de Janeiro as febres foram particularmente mortíferas. Tal número elevado de mortes provocou grandes mudanças na política de saúde do Império, inclusive na região onde estava localizada a povoação do Porto das Caixas.

No ano de 1829 , as febres do Macacu causaram na sede da Vila Santo Antônio de Sá e no arraial do Porto das Caixas tamanha desolação que as famílias mais abastadas fugiram da localidade, estabelecendo residência na Freguesia de São João de Itaborahy (também pertencente a Santo Antônio de Sá), um local um pouco menos afetado pelas febres:

A Febre de Macacú, que a Commissão Medica para alli mandada pelo governo chamou de endemica, despovoou já essa miseravel Villa; e ora continua a fazer seus terríveis estragos no Porto das Caixas, Villa Nova, S. João de Itaborahy, \&c.; e tal he a força com que acommette aos doentes, que (segundo diz huma carta que vi do Porto das Caixas) tem acontecido de estarem boas ao meio dia pessoas, que a noite já não existem. O único Cirurgião, que havia em Villa Nova, e Porto das Caixas acaba de ser também atacado e se acha por consequencia impossibilitado de ministrar soccorros aos inumeráveis doentes (A AURORA FLUMINENSE, 1829, p. 750).

Foi tão severa a situação da população local que correspondências de moradores ao periódico A Aurora Fluminense foram encontradas, ora informando os males causados pelas febres, ora pedindo providências ao governo para tal situação:

Eu só tive por fito nessa correspondência, lembrar ao ministro do império que as providencias por ele dadas não tinhão sido suficientes; que as febres continuavão a fazer progressos ater-

3 Existem mais de uma centena de títulos antigos para designar um sistema de febres: febre perniciosa, febre biliosa, febre pútrida, febre exantemática, febre tifoide, febre amarela, febre intermitente, febre renitente etc. 


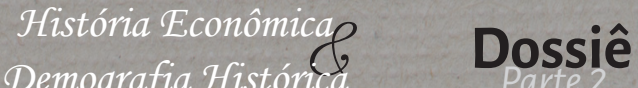

radores em Macacú, por acumulo de desgraça, houvesse então nesses lugares Cirurgiões, que aos doentes ministrassem os socorros indispensáveis [...] Mas em fim seja o que for; a minha correspondência de então teve (ao menos essa foi a minha intenção) o mesmo fim, que esta agora; isto he, chamar a atenção do ministro do império sobre os males, que continuão a sofrer os habitantes do Macacú, Villa Nova, Porto das Caixas (A AURORA FLUMINENSE, 1829, p. 810).

Segundo Maria Luiza Marcílio (1993, p. 53), depois do ano de 1830 até os primeiros anos do século XX, o número de óbitos superou o de nascimentos na província do Rio de Janeiro, motivado em grande parte pelas epidemias de febres, sendo a febre amarela responsável por mais de 4 mil mortes. Tal mortalidade ocasionou mudanças políticas e administrativas na região do Vale do Macacu, onde os surtos tiveram início.

Em 15 de janeiro de 1833, devido à insalubridade da Vila Santo Antônio de Sá e por meio de um decreto Imperial, a Freguesia de São João de Itaborahy foi elevada à categoria de Vila de São João de Itaborahy, que passou a incorporar o arraial do Porto das Caixas. A criação da capela filial curada do arraial só ocorreu em 2 de maio de 1844, quando o arraial do Porto das Caixas também assumiu o título de curato de Nossa Senhora Imaculada Con-

A região do curato de Nossa Senhora Imaculada Conceição do Porto das Caixas, atacada no ano de 1828 pelas "Febres do Macacu", viu-se novamente assolada por outra epidemia já na década de 1850, mais precisamente em 1855, quando chegaram à província do Rio de Janeiro os primeiros casos de Chólera Morbus. ceição do Porto das Caixas, sob a cura do padre João Lourenço Filgueiras (JORNAL DO COMMERCIO, 1846, p. 3).

\section{A chegada da Chólera Morbus no Porto das Caixas:}

A região do curato de Nossa Senhora Imaculada Conceição do Porto das Caixas, atacada no ano de 1828 pelas "Febres do Macacu", viu-se novamente assolada por outra epidemia já na década de 1850 , mais precisamente em 1855 , quando chegaram à província do Rio de Janeiro os primeiros casos de Chólera Morbus.

No início do ano de 1830, a epidemia de Chólera Morbus atingiu a Europa Ocidental, trazendo preocúpações aos médicos brasileiros. Atendendo a um pedido da Câmara dos Deputados, os mé- 
dicos da Sociedade de Medicina do Rio de Janeiro apresentaram alguns "conselhos às autoridades no caso de ameaça ou invasão do Chólera-Morbus" (PIMENTA, 2013, p. 1), como forma de preparação para a chegada da epidemia em nossos portos, fato que não tardou a acontecer.

O primeiro caso da doença relatado oficialmente na província do Rio de Janeiro ocorreu em junho de 1855 , quando um escravo pardo, de nome Maximiano, chegou da província do Ceará a bordo do vapor S. Salvador. Maximiano desembarcou e foi para a casa do seu senhor, ficando doente três dias depois, mais precisamente do dia 15 de junho daquele ano 1855. O escravo que compartilhou a cama com Maximiano logo também adoeceu, vindo a óbito após dez horas do início dos sintomas (RECO, 1873, p. 106). A partir de então, a epidemia se espalhou pela província, chegando rapidamente ao curato de Nossa Senhora Imaculada Conceição do Porto das Caixas, através dos barcos que vinham do porto do Rio de Janeiro: "Nas margens do Rio Macacú, em Villa Nova e no Porto das Caixas appareceo a chólera em setembro levado pelos barcos que diariamente communicavão com a corte" (RELATÓRIO ACERCA DA SAÚDE PÚBLICA, 1856).

Em uma publicação do Correio Mercantil, e Instructivo, Político, Universal do dia 23 de setembro de 1855, três meses após o surgimento do primeiro caso de Chólera Morbus na província, foi relatado

A situação da epidemia de cólera no Porto das Caixas preocupou as autoridades, principalmente pelo grande fluxo de pessoas que passavam pela região, além do fator geográfico da localidade. Rodeada por pântanos e águas estagnadas, a região favoreceu um ambiente propício para a propagação da doença, juntamente com falta de saneamento básico e de condições higiênicas, sobretudo nas escravarias locais. que "um preto de uma lancha do Porto das Caixas, com os sintomas da chólera, chegou em Paquetá pedindo ajuda" (CORREIO MERCANTIL, 1855, p. 1). Seis dias depois, a situação do Porto das Caixas foi descrita como "moléstia reinante, com três casos fataes" (A CONSTITUIÇÃO, 1855, p. 4).

A cólera foi considerada mortífera e bárbara, pois além de matar metade daqueles que contaminava, matava de forma cruel e em poucas horas (SAN]AD, 2004, p. 588). E mesmo acostumada a conviver com o alto grau de mortalidade e inúmeras epidemias, a população entrou em desespero por conta da doença. No ano de 1855 , enquanto o número de óbitos na província do Rio de Janeiro foi de 11.180 , o número de nascimentos foi de 6.660 - diferença que se deve, principalmente, à cólera (MARCílIO, 1993, p. 53-54).

A situação da epidemia de cólera no Porto das Caixas preocupou as autoridades, principalmente pelo grande fluxo de pessoas que passavam pela 
região, além do fator geográfico da localidade. Rodeada por pântanos e águas estagnadas, a região favoreceu um ambiente propício para a propagação da doença, juntamente com falta de saneamento básico e de condições higiênicas, sobretudo nas escravarias locais. Segundo Jorge Prata de Sousa (2006, p. 2), a questão da falta de condições higiênicas e sanitárias deve ser sintetizada em uma hipótese genérica, como fator determinante nos índices de mortalidade e, também, no perfil da morbidade. Assim, fica claro que a utilização das águas contaminadas e paradas da região e a falta de condições higiênicas favoreceram o desenvolvimento da epidemia de cólera local e estavam intimamente relacionadas com os números de óbitos pela doença. Mas não só isso. $O$ grande fluxo de pessoas que transitavam pela região contribuiu para a propagação de casos de Chólera Morbus.

As notícias publicadas nos periódicos sobre a epidemia de Chólera Morbus da região continuaram a crescer. No dia 5 de outubro de 1855, foi informada a morte de três negros marinheiros, que faziam viagens da corte para o Porto das Caixas (CORREIO MERCANTIL, 1855a, p. 1). Já no dia 9 de outubro, foi publicado o relato do Dr. Fortes, que noticiava dois falecimentos no local, e mais um escravo morto na fazenda Sampaio, que sucumbiu à doença em apenas quatro horas. Além desse escravo, mais quatro da mesma fazenda ficaram doentes, melhorando após alguns dias (CORREIO MERCANTIL, 1855b, p. 1). A fazenda Sampaio continuou tendo sua escravaria atacada, com nove mortos no dia 21 de outubro (CORREIO MERCANTIL, 1855c, p. 1).

O relatório sobre o período de 19 de setembro a 26 de novembro de 1855 , feito pelo vice-presidente da província, Visconde de Baependy, deixou explícita a preocupação com a situação da cólera na região do Porto das Caixas. Esse relatório informou quatro casos de coléricos no Porto, todos escravos da corte que faziam viagens para o local, dois dos quais fatais. Baependy nomeou uma comissão filial na localidade para controlar e ajudar os doentes, da qual fez parte o comendador Antônio José Rodrigues Torres, o irmão do Visconde de Itaborahy. Além disso, foi montada uma enfermaria na região, responsável pelos primeiros atendimentos, já que os doentes mais graves, quando possível, eram enviados para o hospital em Jurujuba. Nesse mesmo relatório, foi informado que a escravaria da fazenda Sampaio estava sendo atacada pela epidemia, com mais de vinte escravos adoentados e nove mortos (RELATÓRIO DO VICE-PRESIDENTE, 1855, p. 21-22).

O relatório da enfermaria montada no Porto das Caixas, referente ao dia 16 de outubro de 1855, descreveu a entrada de dezoito doentes, dos quais dois faleceram, quatro tiveram alta e o restante ainda permanecia em tratamento. Desesperada com o aumento de casos, a população recorreu a promessas e rezas, a fim de salvar a localidade do avanço da doença. O próprio comendador Antônio José Rodrigues Torres fez uma promessa a Santo Antônio, pagando com 
missas, festas e rezando trezenas descalço, se a doença fosse eliminada da localidade (CORREIO MERCANTIL, 1855d?, p. 1).

Ao analisar as informações oficiais e as notícias publicadas nos periódicos, percebe-se que a' cólera no curato de Nossa Senhora Imaculada Conceição do Porto das Caixas atingiu principalmente os escravos, fato esse que também ocorreu em outras localidades da província do Rio de Janeiro. Em uma publicação do século XIX, o Dr. José Pereira Rego deixou bem clara a "preferência da doença" pelos escravos e pela população mais pobre:

Esta epidemia atacou de preferencia os pretos, os homens de côr e as classes mais inferiores da sociedade [...]. As outras classes sociaes, sobretudo as mais elevadas quasi nada soffreram, porque poucas foram as victimas dadas entre ellas, e essas mesmas de ordinário só appareciam quando os affectados, ou desprezavam a moléstia em seu principio, ou commettiam grandes infracções dos preceitos hygienicos (RECO, 1873, p. 109).

A suposta preferência pelos escravos e pelos mais pobres se deve às condições de higiene em que viviam essas populações, que facilitavam o contágio e a disseminação da cólera. Para Kaori Kodama (2012, p. 62-64), a mortalidade mais intensa entre a população escrava e pobre em geral foi atribuída pelo pensamento médico dominante no Brasil aos costumes, à dieta e ao ambiente, conforme o modelo higienista então em voga. Segundo Kodama, esse pensamento fez com que o governo recomendasse que os escravos nas fazendas tivessem alimentação adequada, fossem bem agasalhados, não trabalhassem muito tempo em rios ou pântanos e que as senzalas não ficassem "em lugares baixos, sombrios e úmidos; como algumas atualmente se àcham nestas más condições”. Além disso, suas moradas deveriam ser varridas, arejadas, deixando-se entrar sol, e os dejetos deveriam ser dispensados a certa distância. Apesar das recomendações, muitos senhores continuavam a propiciar um ambiente inóspito e facilitador de doenças aos seus escravos, em inúmeras vezes negandó-se a relatar o número legítimo de ocorrências de doentes e mortos em suas escravarias, fato esse que contribui para a incerteza do número real de escravos atingidos pela cólera. Muitos escravos eram obrigados a trabalhar em condições insalubres, como pode-se ver na descrição das enchentes dos pântanos da região do Porto das Caixas:

Há quinze dias as chuvas continuadas tem causado extraordinária enchente no Macacu. Os campos estão inundados, o aterro Tipotá está cinco palmos d'água acima do seu nível e os pobres escravos são obrigados a passar com as águas na altura do peito (CORREIO MERCANTIL, . 1855 e?, p. 1). 


\section{Considerações finais}

Não é de se estranhar o alto número de escravos atingidos na região da Baía de Guanabara pela cólera. Além do contato constante com os doentes da corte devido ao alto fluxo de pessoas que por lá passavam, os escravos também eram expostos a condições de higiene precárias e em contato com águas contaminadas. Apesar do elevado números de mortes, principalmente de escravos no Porto das Caixas, a epidemia foi regredindo no mês de novembro, sendo considerada quase extinta em dezembro de 1855 , salvo de alguns casos benignos relatados (CORREIO MERCANTIL1855f?, p. 1). Mesmo assim, a comissão eleita reservou, no mesmo mês, a quantia de setecentos e cinquenta réis para o médico local, a fim de tratar de novos casos que surgissem (CORREIO DA TARDE, 1855, p.1).

O importante porto fluvial do curato de Nossa Senhora Imaculada Conceição do Porto das CaiXas foi vítima, no século XIX, de grandes epidemias que atingiram grande parte da sua população, dificultando a vida dos moradores da região e o comércio local. Primeiro com as febres do Macacu e depois com a Chólera Morbus, a região tinha como agravante para os surtos de doenças a predisposição geográfica, já que era cercada por pântanos e áreas alagadiças, que facilitavam a disseminação dessas doenças. Apesar de ter sua população atacada constantemente por surtos epidêmicos, a região continuou com o seu comércio em crescimento e seu prestígio político, sendo elevada à categoria de vila em 17 de outubro de 1856 .

Os periódicos tiveram a função importantíssima de relatar a chegada e o avanço da doença, com a descrição dos números de contaminados e dos óbitos. Apesar do alto índice de mortalidade, o pico da epidemia ocorreu somente no ano de 1855, em dezembro do mesmo ano a epidemia chegou ao fim na região. Após a análise dessas notícias, ficou claro que o Chólera Morbus chegou ao Porto das Caixas através dos escravos marinheiros, que trouxeram a doença da corte. Também ficou em evidência o alto número de escravos locais atingidos pela epidemia e a alta taxa de mortalidade desse grupo social em detrimento aos outros, principalmente pelas condições higiênicas em que eram obrigados a viver. Percebe-se, também, que a Fazenda Sampaio foi a que mais teve sua escravaria atingida, fato que pode ser esclarecido devido à proximidade dessa propriedade com as regiões pantanosas e de águas estagnadas do Vale do Macacu. 


\section{Referências}

BRASIL. Ministério do Império. Relatório acerca da Saúde pública feito pelo Dr. Francisco de Paula Cândido no anno' de 1856. Disponível em: <http://memoria.bn.br/pdf/720968/per720968_1856_00001.pdf>. Acesso em: 3 jun. 2016.

RIO DE JANEIRO (Província). Relatório apresentado a Assembleia Legislativa da Província do Rio de Janeiro, na $2^{\mathrm{a}}$

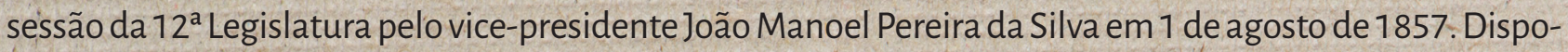
nível em: <http://brazil.crl.edu/bsd/bsd/787/000072.html>. Acesso em: 26 jun. 2016.

RIO DE JANEIRO (Província). Relatório do vice-presidente da província Visconde de Baependy do período de 79 de setembro a 26 de novembro de 7855. Disponível em: <http://brazil.crl.edu/bsd/bsd/u832/000020.html>. Acesso em: 12 jan. 2017.

CABRAL, Diogo de Carvalho. Homens eárvores no ecúmeno colonial. Uma história ambiental da indústria madeireira na bacia do Macacu, Rio de Janeiro, 1763-1825. Dissertação (Mestrado em História Social) - Universidade Federal do Rio de Janeiro, Rio de Janeiro. 2007.

CALÓGERAS, Pandiá. Transportes arcaicos. [O jornal - Edição comemorativa do bicentenário do cafeeiro no Brasil]. São Paulo: Palácio das Indústrias, 1927. v. 1.

CASAL, Manuel Aires de. Coreografia brasílica ou Relação histórico-geográfica do Reino Brasil (1817). São Paulo: Edusp, 1976.

DIAS, Maria Odília Leite da Silva. A interiorização da Metrópole e outros estudos. São Paulo: Alameda, 2005.

FORTE, José Matoso Maia. Vilas fluminenses desaparecidas. Revista da Sociedade de Ceografia do Rio de Janeiro, Rio de ]aneiro [Biblioteca Nacional], v. 44, 1937.

GEICER, Pedro Pinchas; SANTOS, Ruth Lyra. Notas sobre a evolução da ocupação humana na baixada fluminense. Revista Brasileira de Geografia, Rio de Janeiro, v. 16, n. 3, jul./set.1954. Disponível em: <http://www. bvambientebf.uerj.br/banco_de_imagens/artigos_rbg/RBC_1954_evolacao_ocupacao.pdf>. Acesso em: mar. 2018.

KODAMA, Kaori. Mortalidade escrava durante a epidemia de cólera no Rio de Janeiro (1855-1856): uma análise preliminar. História, Ciências, Saúde-Manguinhos, Rio de Janeiro, v. 19 [supl.], dez. 2012.

LENHARO, Alcir. As tropas da moderação: o abastecimento da Corte na formação política do Brasil, 18081842. São Paulo: Símbolo, 1979.

MACHADO, Lia Osório. Cente do Caceribu, sua geografia, sua história. [Projeto "Cente do Caceribu"]. Rio de Janeiro: UFR], 1998. Disponível em:<http://www.retis.igeo.ufrj.br/wp-content/uploads/1998-gente-do-Caceribu-LOM.pdf>. Acesso em: 10 fev. 2016. 
MARCÍLIO, Maria Luiza. Mortalidade e morbidade da cidade do Rio de Janeiro Imperial. Revista de História, São Paulo, n. 127-128, p. 53-68, [ago./dez. 1992] jan./jul. 1993. Disponível em: <http://www.revistas.usp. br/revhistoria/article/viewFile/18689/20752>. Acesso em: 9 out. 2016.

MIZUBUTI, Satiê. Sobre a formação da mão-de-obra industrial no Brasil e a imigração estrangeira- 1890 1930. GEOgraphia, Niterói, v. 3, n. 5, p. 47-57, jan./jun. 2001. Disponível em: <http://www.geographia.uff. br/index.php/geographia/index>. Acesso em: mar. 2018.

NOCUEIRA, Viviany Barreto. A peregrinação em Porto das Caixas. O espaço sagrado modelando a dinâmica na paisagem. Dissertação (Mestrado em Urbanismo) - Universidade Federal do Rio de Janeiro, Rio de Janeiro. 2009.

OLIVEIRA, Rafael da Silva. Os eixos de transporte e as transformações na organização espacial do Recôncavo da Cuanabara entre os séculos XVIII eXIX: os exemplos de Iguaçu e Estrela. Revista do Instituto Histórico e Geographico Brazileiro, Rio de Janeiro, v. 168, n. 435, p. 91-117, abr./jun. 2007. Disponível em: <https://ihgb. org.br/publicacoes/revista-ihgb/item/158-volume-435.html>. Acesso em: mar. 2018.

PIMENTA, Tânia Salgado. O Estado da Misericórdia (Rio de Janeiro, século XIX). Conhecimento histórico e diálogo social. In: SIMPÓSIO NAC̣IONAL DE HISTÓRIA, 27., 2013, Natal. Anais... Natal: Anpuh, 2013. Disponivel em: <http://www.snh2013.anpuh.org/resources/anais/27/1364476703 ARQUIVO TaniaPimentaanpuh2013.pdf>. Acesso em: 24 jan. 2017.

PINTO, Luiz Maria da Silva. Diccionario da Lingua Brasileira. Ouro Preto: Typographia de Sila, 1832.

RECO, José Pereira. Memória histórica das epidemias de febre amarella e chólera-morbo que têm reinado no Brasil pelo Dr. José Pereira Rego. Rio de Janeiro: Typographia Nacional, 1873.

ROCHA, Helenice Aparecida Bastos et al. Caixa da história: Itaboraí. São Conçalo: UERJ/FFP, 2011.

ROSA JUNIOR, Ailton Fernandes da. Em águas turvas: homens livres pobres no Vale do Macacu oitocentista. Dissertação (Mestrado em Ciências) - Universidade Federal Rural do Rio de Janeiro, Serópédica. 2014.

ROSEDAHL, Zeny. Espaço Sagrado: o exemplo de Porto das Caixas, Baixada Fluminense. Revista Brasileira de Ceografia, Rio de Janeiro, v. 57, n. 1, p. 53-72, jan./mar. 1995.

SAMPAIO. Antônio Carlos Jucá de. Os homens de negócio cariocas da primeira metade do setecentos: origem, alianças e acumulação na construção do espaço atlântico: Disponível em: <http://cvc.instituto-camoes.pt/ eaar/coloquio/comunicacoes/antonio_juca_sampaio.pdf>. Acesso em: 5 dez. 2016.

SANJAD, Nelson. Cólera e medicina ambiental no manuscrito "Cholera-morbus" (1832), de Antonio Correa de Lacerda (1777-1852). História, Ciências, Saúde-Manguinhos, [online], v. 11, n. 3, p. 587-618, set./dez. 2004. Disponivel em: <http://www.scielo.br/scielo.php?script=sci arttext\&pid=S0104-59702004000300004\&In $\mathrm{g}=\mathrm{en} \& \mathrm{nrm}=\mathrm{iso}>$. Acesso em: mar. 2018. http://dx.doi.org/10.1590/S0104-59702004000300004. 
SANTOS, Milton. A natureza do espaço: técnica e tempo, razão e emoção. 4. ed. São Paulo: Edusp, 2006.

SATHLER, Evandro Bastos. Tropeiros e outros viajantes. Niterói: UFF, 2003.

SOUSA, Jorge Prata de. Os registros de óbitos da Santa Casa de Misericórdia do Rio de Janeiro, 18351849. Usos do Passado. ENCONTRO REGIONAL DE HISTÓRIA, 12., 2006, Rio de Janeiro, Rio de Janeiro: Anpuh, 2006. Disponivel em: <http://rj.anpuh.org/resources/ri/Anais/2006/conferencias/Jorge\%20 Prata\%20de\%20Sousa.pdf>. Acesso em: 27 jan. 2017.

SOUZA, Laura de Mello e. O sol e a sombra: política e administração na América Portuguesa do século XVIII. São Paulo: Companhia das Letras, 2006.

\section{Periódicos consultados:}

A AURORA FLUMINENSE. Rio de Janeiro, n. 181, 24 abr. 1829.

A CONSTITUIÇÃO. Rio de Janeiro, v. 1, n. 43, 29 set. 1855.

Correio da Tarde. Rio de Janeiro, v. 1, n. 113, 26 dez. 1855.

Correio Mercantil, e Instructivo, Político, Universal. Rio de Janeiro, v. 12, n. 275, 5 out. 1855 a.

Correio Mercantil, e Instructivo, Político, Universal. Rio de Janeiro, v. 12, n. 263, 23 set. 1855.

Correio Mercantil, e Instructivo, Político, Universal. Rio de Janeiro, v. 12, n. 279, 9 out. 1855 b.

Correio Mercantil, e Instructivo, Político, Universal. Rio de Janeiro, v. 12, n. 291,21 out. 1855 c.

Correio Mercantil, e Instructivo, Político, Universal. Rio de Janeiro, v. 12, n. 347, 18 dez. 1855 d.

Correio Mercantil, e Instructivo, Político, Universal. Rio de Janeiro, v. 12, n. 13, 14 jan. 18,55e.

Correio Mercantil, e Instructivo, Político, Universal. Rio de Janeiro: v. 1,2, n. 331, 1 dez. $1855 f$.

Jornal do Commercio. Rio de Janeiro, v. 21, n. 311, 9 nov. 1846. 